\title{
The course and determinants of insulin action in Type 1 (insulin-dependent) diabetes mellitus
}

\author{
H. G. T. Nijs, J.K. Radder, M.Frölich and H.M.J.Krans \\ Department of Endocrinology and Metabolic Diseases, University Hospital, Leiden, The Netherlands
}

\begin{abstract}
Summary. The course and determinants of insulin action were investigated in 8 newly diagnosed Type 1 (insulin-dependent) diabetic patients, who were studied every 3 months for one year, and in three groups of 8 patients each with 5, 10 and 20 years diabetes, studied once. Fifteen healthy subjects matched for age, sex and body weight served as control subjects. Dose-response curves were constructed using sequential euglycaemic $(5.0 \mathrm{mmol} / \mathrm{l})$ clamps (insulin infusion rates: 0.5 , $1.0,2.0$ and $5.0 \mathrm{mU} \cdot \mathrm{kg}^{-1} \cdot \mathrm{min}^{-1}$ in periods of $2 \mathrm{~h}$ ). After $1 / 2$ month of insulin treatment, insulin responsiveness was normal, but sensitivity was decreased $\left(\mathrm{ED}_{50} 70 \pm 7 \mathrm{mU} / 1\right.$ (SEM) vs $54 \pm 4 \mathrm{mU} / 1$ in control subjects, $p<0.05$ ). After 6 months, insulin sensitivity was improved (ED50 $57 \pm$ $4 \mathrm{mU} / 1, p<0.01 \mathrm{vs}^{1} / 2$ month and not significant (NS) vs control subjects); but after 9 and 12 months, it was reduced again, similarly to 0.5 month. Insulin responsiveness remained nor-
\end{abstract}

mal at all time-points. In the three groups of patients with longstanding diabetes, impaired insulin sensitivity with normal responsiveness was noted also $\left(\mathrm{ED}_{50} 73 \pm 9 \mathrm{mU} / 1\right.$, $p<0.02$ vs control subjects). At 6,9 and 12 months, glycaemic control $\left(\mathrm{HbA}_{1}\right)$ and insulin dose were inverse correlates for insulin action; in patients with longstanding disease, this was noted for $\mathrm{HbA}_{1}$ and body weight, in control subjects for body weight. In conclusion, decreased insulin sensitivity re-develops in Type 1 diabetes within the first year following an initial improvement. Presumably, hyperglycaemia plays a role in the pathogenesis of this recurrence.

Key words: Insulin resistance, time-course, euglycaemic clamp, Type 1 (insulin-dependent) diabetes, insulin action, glycaemic control.
The course and determinants of insulin action have been investigated infrequently in a prospective fashion in Type 1 (insulin-dependent) diabetes. In cross-sectional studies, insulin action was decreased during ketoacidosis [1], improved after short-term insulin treatment $[2,3]$ and decreased again in patients with longstanding disease [4-11]. A similar time-course was found in one prospective study after $0.5,3$ and 12 months of treatment [12].

In most studies employing clamp techniques, insulin action was assessed at only one or two (submaximal) insulin levels. When more insulin levels are employed, dose-response curves can be constructed and insulin resistance can be characterised further in terms of insulin insensitivity and/or unresponsiveness [13, 14]. In addition, the difficulty of comparing insulin action at different steady-state insulin levels - usually avoided by dividing some measure of insulin action by the achieved insulin level [3] - is hereby circumvented.

To examine the course and determinants of insulin action, we extended our in vivo dose-response studies in newly diagnosed Type 1 diabetic patients [15] to 6,9 and 12 months. In addition, three groups of patients with diabetes durations of 5, 10 and 20 years were studied once. Fifteen healthy subjects matched for age, sex and body weight served as control subjects. Using sequential euglycaemic clamps, dose-response curves for insulin-stimulated glucose disposal were constructed. With this study-design, changes in insulin sensitivity or responsiveness can be monitored and relations between clinical variables and insulin action can be examined, which may lead to more insight into the time-course and pathogenesis of insulin resistance.

\section{Subjects and methods}

Four groups of diabetic patients were studied. The first group ( $n=8$, referred to as prospective study) had newly diagnosed Type 1 diabetes and was investigated every 3 months for one year, following the initia- 
Table 1. Characteristics of patients with Type 1 (insulin-dependent) diabetes grouped according to duration of insulin treatment, and of control subjects

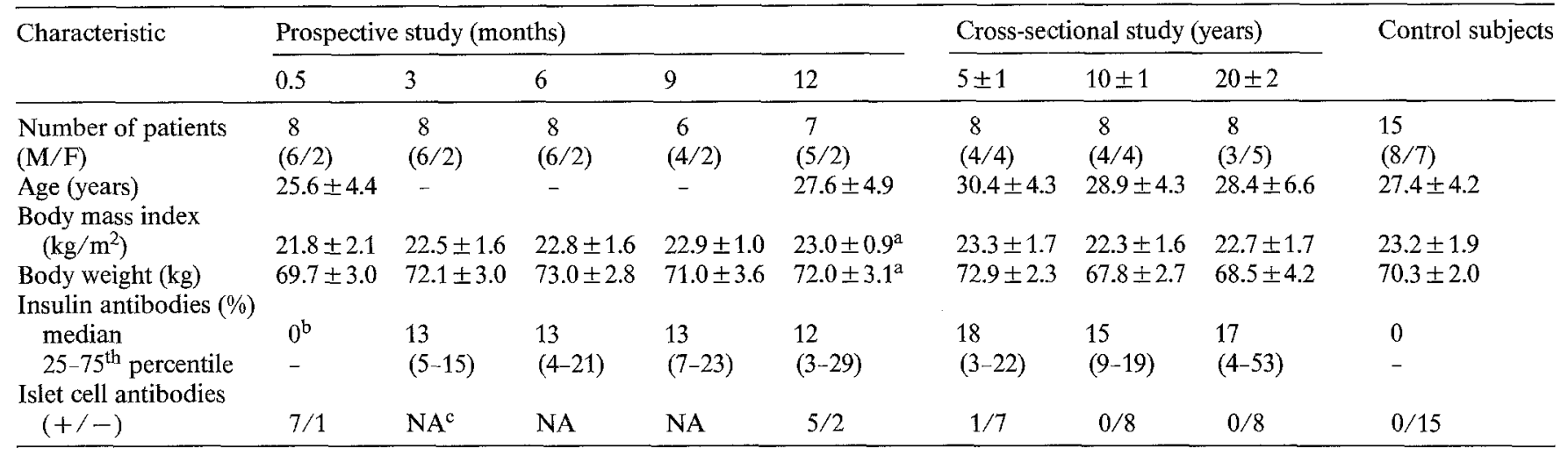

Results are mean \pm SEM, unless indicated otherwise. ${ }^{\mathrm{a}} p<0.02$ ( 0.5 to 12 months); ${ }^{\mathrm{b}} p<0.02$ (3 to 12 months), $p<0.01$ vs time-points of the crosssectional study (Kruskal Wallis); ${ }^{c} \mathrm{NA}=$ not available

tion of insulin treatment. The other three groups (each $n=8$, referred to as cross-sectional study) had mean durations of diabetes of 5 (range $3-7), 10(8-14)$ and $20(15-32)$ years, respectively. These patients were investigated once. Fifteen islet cell antibody (ICA)-negative healthy subjects with comparable sex, age and body weight were investigated once. None had a family history of diabetes and all had a normal oral glucose $(75 \mathrm{~g})$ tolerance test [16]. Four healthy subjects were restudied one year after their first clamp. All subjects were using a weight-maintaining diet containing at least $200 \mathrm{~g}$ of carbohydrate per day. Characteristics of patients and healthy subjects are shown in Table 1 .

Patients in the prospective study received a combination of shortand intermediate-acting human insulin (Actrapid and Monotard HM, Novo, Copenhagen, Denmark). Adjustments of the insulin dose were made by the patients' physicians without knowing the results of the clamp studies. Patients in the cross-sectional study were treated similar, except for five who used porcine and one who used bovine insulin. One patient in the prospective study had coronary heart disease and hypertension, for which he was treated with digoxin and propranolol. This medication was not changed during follow-up. In the group with 10 years diabetes, two patients had background retinopathy. Another patient in this group had epilepsy, hypertension, diabetic retinopathy and neuropathy, for which she was treated with phenobarbital, diphenylhydantoin, furosemide and atenolol. In the group with 20 years diabetes, four patients had background retinopathy. The nature, purpose and potential risks of the study were explained to all participants and their consent was obtained before participation. The study protocol has been approved by the Ethical Committee of the University Hospital Leiden, The Netherlands.

\section{Insulin action in vivo}

The sequential euglycaemic clamp technique [17, 18], as described previously [15], was used to quantify insulin action in vivo. Control subjects were admitted on the day of the study (07.30 hours) after an overnight fast (10-12 h). Diabetic patients were admitted to the hospital the day before the study at 18.00 hours. During the subsequent evening and night, insulin (Actrapid HM) was administered with a syringe perfusor into an antecubital vein of the left arm to attain or maintain normoglycaemia until the start of the clamp study. A gradual reduction of glucose levels was achieved (pre-dinner $9.5 \pm 1.0$ (SEM) $\mathrm{mmol} / \mathrm{l}$, midnight $6.5 \pm 1.0 \mathrm{mmol} / 1$ and basal $4.8 \pm 0.7$ $\mathrm{mmol} / 1$ ), except for the group with 20 years diabetes, in which the mean basal glucose level was $8.5 \pm 0.9 \mathrm{mmol} / 1$. The clamp was started when the basal glucose level was between 4.5 and $5.5 \mathrm{mmol} / 1$. When the basal plasma glucose level was outside this range, glucose $(20 \%)$ was infused or a bolus of insulin (1-4 U) was administered intraven- ously (i.v.), and the clamp was started $30 \mathrm{~min}$ after the glucose level came within the range of $4.5-5.5 \mathrm{mmol} / \mathrm{l}$.

Insulin (Actrapid $\mathrm{HM}$ ) was diluted in $0.9 \% \mathrm{NaCl}$ with $1 \mathrm{ml}$ autologue plasma $/ 50 \mathrm{ml}$ infusate. This solution was administered i.v. by a Watson Marlow 202U/AA infusor (Falmouth, UK) in four consecutive periods of $2 \mathrm{~h}$ at rates of $0.5,1.0,2.0$ and $5.0 \mathrm{mU} \cdot \mathrm{kg}^{-1} \cdot \mathrm{min}^{-1}$ preceded by a priming bolus of $2.5,5,10$ and $50 \mathrm{mU} / \mathrm{kg}[9,17]$. Plasma glucose values were measured every $5 \mathrm{~min}$ in arterialised $\left(55-60^{\circ} \mathrm{C}\right)$ venous blood samples obtained from a forearm or a wrist vein of the right arm $[19,20]$. Concomitant with the insulin infusion glucose $(20 \%)$ was infused with a second pump (Watson Marlow 202U/AA, Falmouth, UK) to maintain the plasma glucose level around $5.0 \mathrm{mmol} / 1$ in all subjects. Arterialised venous blood samples were collected for plasma insulin determinations at $10 \mathrm{~min}$ intervals during steady-state $\left(90-120^{\text {th }}\right.$ min of each period). Urine was collected during the clamp and afterwards to estimate urinary glucose loss; this was, as expected, negligible (i. e. several orders of magnitudes below the exogenous glucose infusion rate). The steady-state glucose infusion rate (SSGIR) was used as measure of insulin action. Dose-response curves were constructed by plotting the steady-state plasma free insulin level vs its corresponding SSGIR.

\section{Logistic transformation of dose-response curves}

Alterations of insulin sensitivity are indicated by a left- or rightward shift of the dose-response curve $[13,14]$. This can be determined by reading the hormone concentration producing the effect midway between minimum and maximum from the curve, i.e. the classic $E D_{50}$ value. In the current study the minimum effect - fasting hepatic glucose production (HGP) in vivo - was not determined, so a 'true' $\mathrm{ED}_{50}$ could not be obtained. Instead, we used the absolute half-maximal effective insulin concentration, here also called $\mathrm{ED}_{50}$. This approach is valid, because in several studies fasting HGP of Type 1 diabetic patients kept normoglyciaemic overnight is similar to that of control subjects $[21,22]$. The curves were linearised with a logistic transformation, because the determination of the $\mathrm{ED}_{50}$ from a curved line, which is drawn by the investigators themselves, is difficult and may be biased. Besides from being objective, another advantage of such a transformation is that all data available are weighted. Log insulin concentration was plotted vs $\log [\mathrm{Y} /(100-\mathrm{Y})]$. $\mathrm{Y}$ denotes the insulin effect (SSGIR) at a particular insulin concentration expressed as percentage of the maximum effect. By doing so, the dose-response curve is transformed into a straight line and the $\mathrm{ED}_{50}$ is given by the intersection of the least squares regression line with the abscissa [23]. Goodness-of-fit was excellent, as judged from the correlation coefficients of the regression lines: $0.986 \pm 0.023$ in diabetic patients and $0.988 \pm 0.039$ in control subjects. 

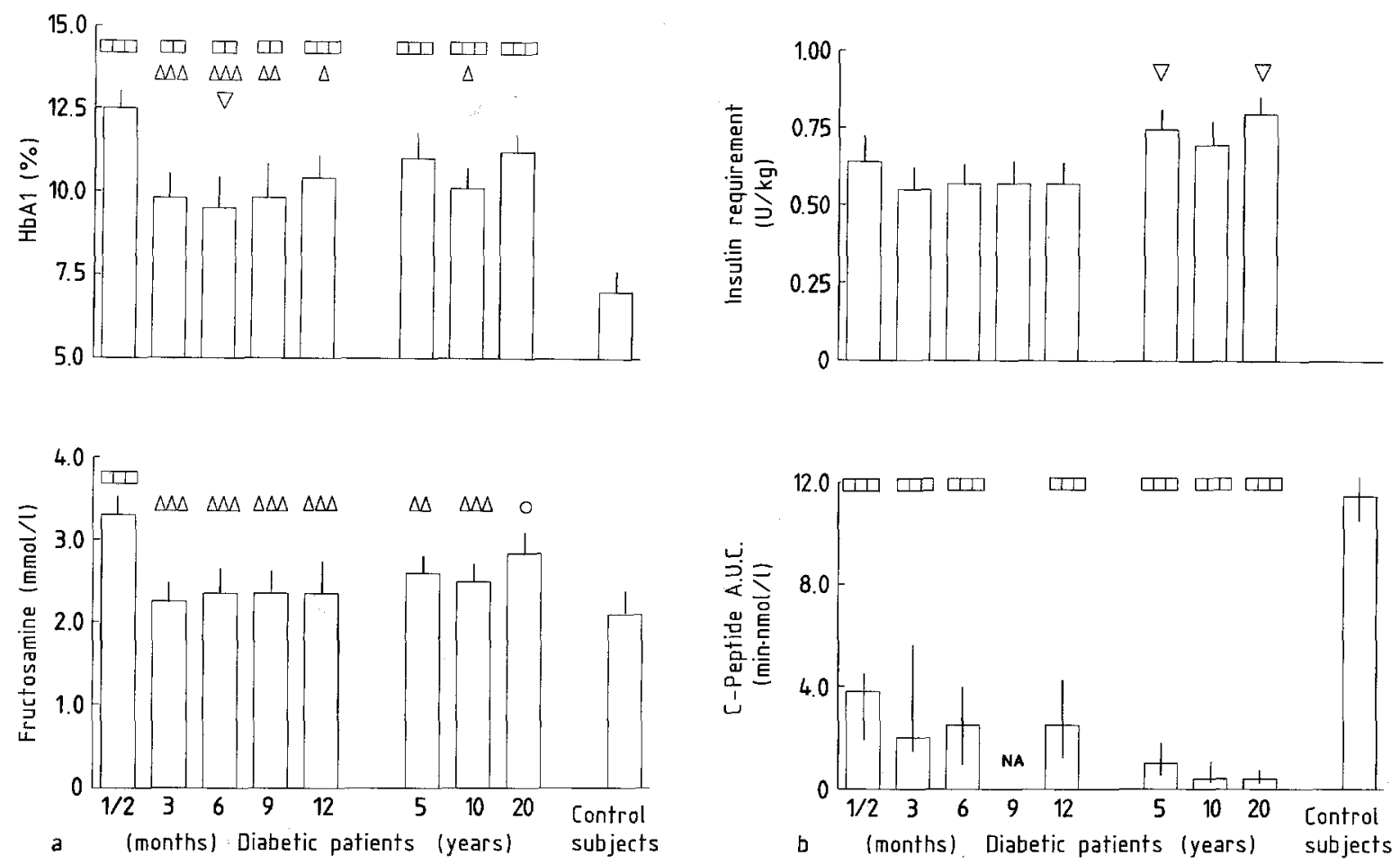

Fig. 1. a HbA $\mathrm{A}_{1}$ and fructosamine in newly diagnosed Type 1 (insulindependent) diabetic patients $(n=8$, time-points marked $1 / 2$ to 12 months), and three patient groups $(n=8)$ with mean durations of diabetes of 5,10 and 20 years. Data represent the mean \pm SEM. Symbols: $\Delta, \Delta \Delta, \Delta \Delta \Delta=p<0.05,0.02$ and 0.01 vs $1 / 2$ month $\square \square$, $\square]=p<0.02$ and 0.01 vs control subjects; $\nabla=p<0.05$ vs 5 , 20 years; $O=p<0.02$ vs 6,9 and 12 months, $p<0.01$ vs 3 months. b Insulin dose and endogenous insulin reserve in newly diagnosed Type 1 diabetic patients ( $n=8$, time-points marked $1 / 2$ to 12 months), and three patient groups $(n=8)$ with mean durations of diabetes of 5 , 10 and 20 years. Endogenous insulin reserve was assessed by measuring C-peptide levels in the fasting state, and 4,6 and 10 min after injecting $1 \mathrm{mg}$ glucagon i.v. Data represent the mean $\pm S E M$ and the median with the $25-75^{\text {th }}$ percentile of the area under the curve (A. U.C.). NA denotes not available. Symbols: $\nabla=p<0.05$ vs 6,9 and 12 months, $p<0.02$ vs 3 months, $\square=p<0.01$ vs control subjects

\section{Endogenous insulin reserve}

On a different day within one week of the clamp study, and once in control subjects, endogenous insulin reserve was determined by measuring C-peptide in the fasting state, and 4,6 and 10 min after injecting $1 \mathrm{mg}$ glucagon i.v. Plasma glucose was between 4 and $10 \mathrm{mmol} / 1$ at the start of the test. Data are represented as total area under the curve (trapezoidal method).

\section{Assays}

Plasma glucose was measured by the glucose oxidase method (Glucose Analyzer II, Beckman Instruments, Palo Alto, Calif, USA) after immediate centrifugation (10 s). Glycated haemoglobin $\left(\mathrm{HbA}_{1}\right)$ was measured by Corning electrophoresis (Palo Alto, Calif, USA). Fructosamine was determined in an auto-analyzer with a colorimetric $(500 \mathrm{~nm})$ reaction. Samples for hormone determinations were kept on ice and centrifuged within $30 \mathrm{~min}$ of collection. The plasma was removed and stored at $-20^{\circ} \mathrm{C}$ until assay. Plasma free insulin levels and plasma C-peptide were determined by radioimmunoassay [24], as described previously [15]. Anti-insulin antibodies were measured by Christiansen's method [25]. Islet cell antibodies were determined by the standard indirect immunofluorescence technique using bloodgroup 0 human pancreas [26].

\section{Statistical analysis}

Comparisons of values were made with analysis of variance (ANOVA), followed by Duncan's multiple comparison test [27-29]. Changes within the prospective study group were analysed using ANOVA for repeated measures. Nonparametric methods (KruskalWallis) were used for data not normally distributed, as verified by Shapiro-Wilk statistics [30]. Simple and multiple partial correlation analysis was performed by standard methods [29]. Calculations were performed on an Apple ${ }^{\mathrm{TM}} \mathrm{IIC}$ personal computer, using Appleworks $^{\mathrm{TM}}$ and StatCalc ${ }^{\mathrm{TM}}$. Data are presented as mean \pm SEM, unless indicated otherwise.

\section{Results}

\section{Clinical characteristics}

In the prospective study, the body weight and body mass index increased from 0.5 to 12 months (Table 1 ). For the cross-sectional groups no differences were found for age, body weight and body mass index, neither with control subjects, nor with any time-point of the prospective study. Notwithstanding treatment with human semi-synthetic insulin, anti-insulin antibodies were found after 3 months (median percentage tracer binding $13 \%$ ). The median value remained $13 \%$ up to 12 months (Table 1). This was similar to patients in the cross-sectional study, among whom 5 were treated with 
H.G.T. Nijs et al.: The course and determinants of insulin action

Table 2. Results of sequential euglycaemic clamp studies ${ }^{\mathrm{a}}$ in patients with Type 1 (insulin-dependent) diabetes grouped according to duration of insulin treatment and in control subjects

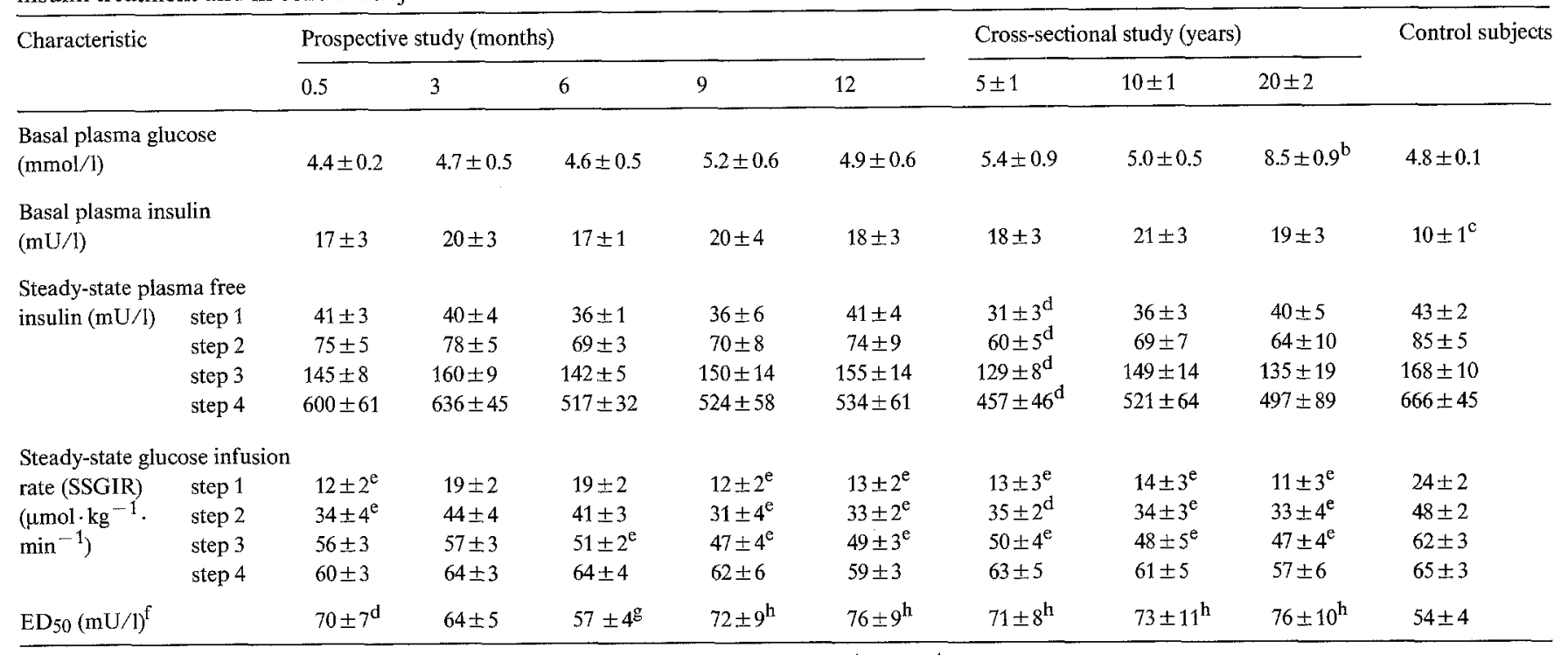

Results are mean \pm SEM, a insulin infusion rates: $0.5,1.0,2.0$ and $5.0 \mathrm{mU} \cdot \mathrm{kg}^{-1} \cdot \mathrm{min}^{-1}$ in four consecutive periods of $2 \mathrm{~h}$, steady-state defined as $90-120^{\text {th }}$ min of each period; ${ }^{\mathrm{b}} p<0.01$ vs other groups of diabetic patients and control subjects; ${ }^{\mathrm{c}} p<0.01$ vs all groups of diabetic patients; ${ }^{\mathrm{d}} p<0.05 ;{ }^{\mathrm{e}} p<0.01$ vs control subjects; ${ }^{\mathrm{f}}$ determined with log-logit analysis (see Methods); ${ }^{\mathrm{g}} p<0.01$ vs 0.5 month; ${ }^{\mathrm{h}} p<0.02$ vs control subjects

porcine and 1 with bovine insulin. At 0.5 month, 7 out of 8 patients, and at 12 months 5 out of 7 patients had antibodies against pancreatic islets. One patient with 5 years diabetes had islet cell antibodies (Table 1).

$\mathrm{HbA}_{1}$ declined from 0.5 to 3 months and remained on average around $9 \%$ until 12 months, still being elevated compared to control subjects $(6.6 \pm 0.2 \% ; p$ at least $<0.05$, Fig. $1 \mathrm{a}$ ). In the three groups with longstanding disease, $\mathrm{HbA}_{1}$ was increased compared to control subjects $(p<0.01)$; in the group with 20 years diabetes, it was also elevated compared to time-point 6 months of the prospective study $(p<0.05)$.

Fructosamine declined from 0.5 to 3 months ( $3.3 \pm 0.2$ to $2.3 \pm 0.1 \mathrm{mmol} / 1, p<0.01$, Fig. 1 a). From 3 to 12 months and in the groups with 5 and 10 years diabetes, the fructosamine level was around $2.3 \mathrm{mmol} / 1$, which was slightly elevated compared to control subjects $(2.1 \pm 0.1 \mathrm{mmol} / \mathrm{l}, \mathrm{NS})$. In the group with 20 years diabetes, fructosamine was increased compared to control subjects and compared to timepoints $3,6,9$ and 12 months ( $p$ at least $<0.02$ ).

Insulin requirements declined from 0.5 to 3 months $(0.60 \pm 0.08$ to $0.54 \pm 0.07 \mathrm{U} / \mathrm{kg}, p=0.06$, Fig. $1 \mathrm{~b})$ and remained at $0.56 \mathrm{U} / \mathrm{kg}$ until 12 months. Patients in the cross-sectional study required more insulin than those in the prospective study; for 5,10 and 20 years diabetes, respectively: $0.79 \pm 0.06$ ( $p$ at least $<0.05$ vs $3,6,9$ and 12 months), $0.72 \pm 0.05$ (NS) and $0.81 \pm 0.06 \mathrm{U} / \mathrm{kg}$ ( $p$ at least $<0.05$ vs $3,6,9$ and 12 months).

Endogenous insulin reserve in the diabetic patients was markedly decreased compared to control subjects on all occasions (Fig. 1b). During the first year of insulin treatment, the median of the integrated responses did not change significantly. The group with 5 years diabetes still had some measurable reserve, although this was low. In the groups with 10 and 20 years diabetes, endogenous insulin reserve was close to or below the detection limit (Fig.1b).

\section{Insulin action}

Basal plasma glucose levels were similar in all groups, except for the group with 20 years diabetes (Table 2). Basal insulin levels were elevated in the diabetic patients compared to control subjects $(p<0.01$, Table 2$)$. Steady-state plasma glucose levels averaged between 4.9 and $5.1 \mathrm{mmol} / \mathrm{l}$ in all groups, with coefficients of variation between 2 and $7 \%$.

Mean steady-state plasma free insulin levels are shown in Table 2. In general, insulin levels tended to be lower in diabetic patients than in control subjects; significant differences were found for patients having 5 years diabetes (step $1-4, p<0.05$ vs control subjects).

In Figures $2 \mathrm{a}-\mathrm{c}$, dose-response curves are depicted; the corresponding SSGIR values are given in Table 2. By visual inspection, the curve was shifted to the right after 0.5 month (Fig. 2 a), within the normal range after 3 and 6 months (Fig. 2 a) and shifted to the right again after 9 and 12 months (Fig. 2 b). In the patients with longstanding disease, the curves were shifted to the right as well (Fig. $2 \mathrm{c}$ ). ED $_{50}$-values are presented in Table 2. After 0.5 month, the $\mathrm{ED}_{50}$ was increased compared to control subjects $(70 \pm 7$ vs $54 \pm 4 \mathrm{mU} / \mathrm{l}$, $p<0.05)$. The $\mathrm{ED}_{50}$ became normal at 6 months $(57 \pm 4 \mathrm{mU} / 1$, NS vs control subjects, $p<0.01$ vs 0.5 month), but was increased again at 9 and 12 months ( $72 \pm 9$ and $76 \pm 9 \mathrm{mU} / 1$, respectively, $p<0.02$ vs con- 


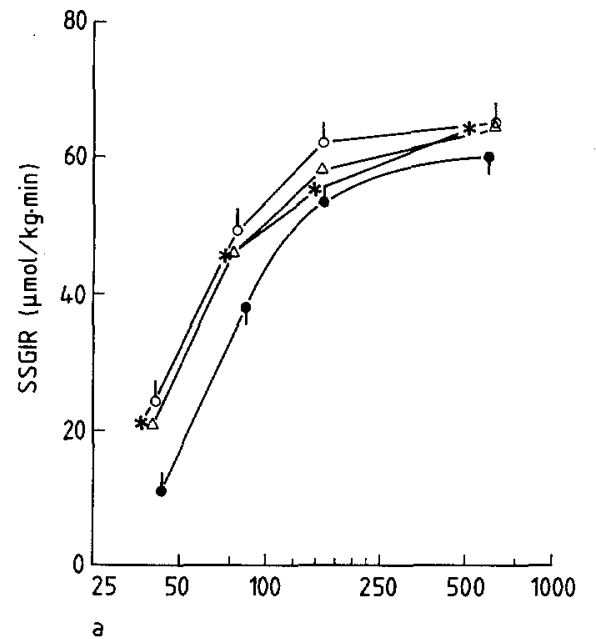

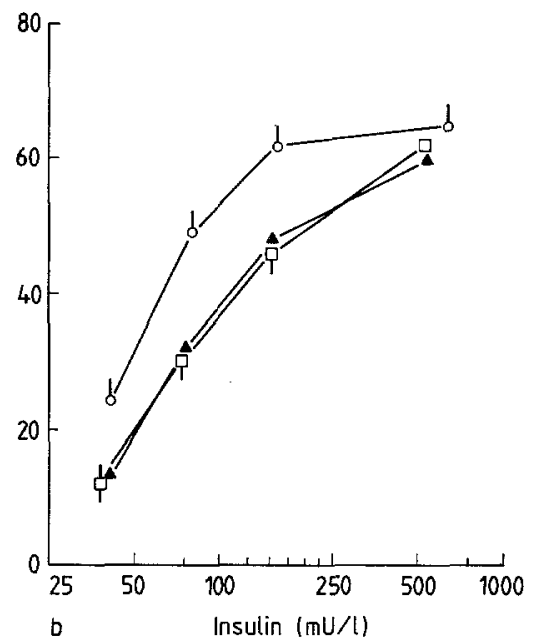

Fig. 2a-c. Dose-response curves for insulin-stimulated glucose disposal in Type 1 diabetic patients, grouped according to duration of insulin treatment: $0.5,3,6$ (a, $n=8$; prospective study), 9, and 12 months (b) and 5, 10 and 20 years (c, $n=8$ each; cross-sectional study), and in 15 control subjects. Insulin action was determined with the sequential euglycaemic $(5.0 \mathrm{mmol} / 1)$ clamp technique, employing insulin infusion rates of $0.5,1.0,2.0$ and $5.0 \mathrm{mU} \cdot \mathrm{kg}^{-1} \cdot \mathrm{min}^{-1}$ in four $2 \mathrm{~h}$-periods. The steady-state $\left(90-120^{\text {th }}\right.$ min of each period) glucose infusion rate (SSGIR) was taken as measure of insulin action, and plotted vs steady-state plasma free insulin level. Data represent the mean \pm SEM. Symbols: $=0.5, \Delta=3, *=6, \square=9$ and $\Delta=12$ months; $O=$ control subjects; $\diamond=5, \Delta=10$ and $=20$ years of Type 1 diabetes

trol subjects and vs 6 months). In the three groups with longstanding diabetes, $\mathrm{ED}_{50}$ was increased to $(71 \pm 8$, $73 \pm 11,76 \pm 10 \mathrm{mU} / 1$, respectively, $p<0.02$ vs control subjects). Maximal SSGIRs were similar to control subjects at all time-points (Table 2).

The percentage variation for the 4 control subjects re-studied after one year was $7 \%$ for the $\mathrm{ED}_{50}$ and $6 \%$ for the maximal insulin response.

\section{Relations between clinical characteristics and insulin action}

Simple and partial regression analysis was used to study the relations between several clinical variables and insulin action. The SSGIRs of the $2^{\text {nd }}$ and $4^{\text {th }}$ infusion period were used as outcome variables, i.e. the effects of insulin at a submaximal level $(80 \mathrm{mU} / \mathrm{l})$ - at which hepatic glucose production is known to be suppressed as well as at a maximal insulin level ( $>450 \mathrm{mU} / 1)$.

For the prospective study, a restricted set of variables was analysed, since the number of patients was limited. Multiple regression models were constructed with glycaemic control $\left(\mathrm{HbA}_{1}\right)$, insulin requirement (U/day) and body weight ( $\mathrm{kg}$ ) as independent variables. At 6, 9 and 12 months, important negative correlates were $\mathrm{HbA}_{1}$ (simple correlation coefficients $\left(\mathrm{r}_{\mathrm{s}}\right)$ from -0.62 to -0.91 , partial correlation coefficients $\left(r_{p}\right.$; the correlation between two variables after the influence of all others has been removed) from -0.62 to -0.92 , $p<0.05$ ) and $\mathrm{U} /$ day $\left(\mathrm{r}_{\mathrm{s}}\right.$ from -0.51 to $-0.67, \mathrm{r}_{\mathrm{p}}$ from -0.58 to $-0.78,0.02<p<0.10)\left(2^{\text {nd }}\right.$ and $4^{\text {th }}$ step). For 0.5 and 3 months, $r_{s}$ or $r_{p}$ never reached significance $(p>0.3)$.

Data from patients with longstanding diabetes were pooled $(n=24)$ to increase the power of the analysis and to allow for the use of a more extended set of variables: $\mathrm{HbA}_{1}$, fructosamine, body weight, body mass index, insulin requirement (U/day), duration of diabetes and age. Important inverse correlates for the SSGIR of the $2^{\text {nd }}$ step were $\mathrm{HbA}_{1}\left(\mathrm{r}_{\mathrm{s}}=-0.55, \mathrm{r}_{\mathrm{p}}=-0.60, p<0.02\right)$, and for the $4^{\text {th }}$ step $\mathrm{HbA}_{1}\left(\mathrm{r}_{\mathrm{s}}=-0.35, \mathrm{r}_{\mathrm{p}}=-0.58, p<0.02\right)$ and body weight $\left(\mathrm{r}_{\mathrm{s}}=-0.31, \mathrm{r}_{\mathrm{p}}=-0.55, p<0.02\right)$. Duration of diabetes was not related to insulin action. The data of the healthy subjects were analysed similarly, without the variables insulin requirement and duration of diabetes. Only body weight was an important negative correlate for the $2^{\text {nd }}\left(\mathrm{r}_{\mathrm{s}}=-0.50, \mathrm{r}_{\mathrm{p}}=-0.54, p=0.07\right)$ and $4^{\text {th }} \operatorname{step}\left(\mathrm{r}_{\mathrm{s}}=-0.52, \mathrm{r}_{\mathrm{p}}=-0.56, p=0.06\right)$.

\section{Discussion}

We investigated the course and determinants of insulin action in Type 1 (insulin-dependent) diabetes. Eight newly diagnosed patients were studied every 3 months for one year, and three groups of patients with 5,10 and 20 years diabetes were studied once to obtain additional cross-sectional data. We chose this combined prospective cross-sectional approach because prospective data collecting for 20 years is impractical. A sequential euglycaemic clamp was employed at three submaximal and one maximal insulin level. Dose-response curves generated with this technique were shifted to the right (i.e. decreased sensitivity with normal responsiveness) 0.5 month after initiating insulin treatment. After 3 and 6 months insulin action was similar to control subjects, but decreased insulin sensitivity reappeared within the next half year and was present in patients 
with longstanding disease. At 6,9 and 12 months, glycaemic control and insulin dose were inverse correlates for insulin action; in patients with longstanding disease, this was noted for $\mathrm{HbA}_{1}$ and body weight, in control subjects for body weight.

Improvement of peripheral insulin action was found in newly diagnosed patients after one week of treatment in a study applying simultaneous infusions of insulin and glucose at two fixed rates [2]. In another study, using single-step clamps, insulin action was improved at a physiological insulin level after 3 months of treatment, while being decreased shortly after ketoacidosis [3]. In patients with longstanding disease, insulin resistance has been documented in many studies using various techniques [4-12]; in one such study, insulin resistance was noted in poorly, but not in well controlled patients [31]. Our study is in accordance with the above. In addition, we show that (1) a similar course of insulin action as in the aforementioned cross-sectional studies appeared in patients followed prospectively for one year; (2) changes in insulin action occurred at submaximal but not maximal insulin levels; (3) presumably, hyperglycaemia plays a role in the pathogenesis of the recurrence of insulin resistance.

Regarding studies utilising sequential clamps, in one study similar findings were noted as in our patients with longstanding disease [9]. At variance, others found both insulin sensitivity and responsiveness to be decreased in six patients treated with continuous s.c. insulin infusion [6]. The reason for this discrepancy is unclear; glycaemic control was comparable to our patients.

In the present study, the temporary improvement of insulin action after 3 to 6 months of treatment did not coincide with a partial recovery of endogenous insulin secretion, as reported by Yki-Järvinen [12]. In the latter study, patients requiring no insulin therapy after 3 months of treatment had a higher SSGIR than their counterparts who were still receiving insulin $(8.6 \pm 0.5$ vs $6.0 \pm 0.5 \mathrm{mg} \cdot \mathrm{kg}^{-1} \cdot \mathrm{min}^{-1}, p<0.002$ ). When patients were re-grouped according to fasting C-peptide levels, the difference remained, but statistical significance was lost. None of our newly diagnosed patients could be treated without insulin. This difference may be due to the fact that patients have been recruited at a different stage of the disease [32]. Unfortunately, the number of patients in our prospective study (eight) was too limited for sub-group analysis.

Hepatic glucose production (HGP) was not determined. In untreated patients, increased fasting HGP and its diminished suppression by insulin can be reversed in 1 week of treatment [2]. Fasting HGP in patients kept normoglycaemic overnight is comparable with non-diabetic control subjects [21, 22]. HGP is suppressed by at least $70 \%$ at insulin levels around $45 \mathrm{mU} / 1$ $\left(1^{\text {st }}\right.$ step of this study) in both diabetic and non-diabetic subjects $[6,12,17,33,34]$; at higher insulin levels, HGP is completely inhibited. Thus, during step 2, 3 and 4 ,
SSGIRs could be equated with glucose disposal rates both in diabetic and non-diabetic subjects and could, therefore, be taken as the sole measure of peripheral insulin action. Fasting HGP averages $10 \mu \mathrm{mol} \cdot \mathrm{kg}^{-1}$. $\min ^{-1}$ [34]. If one assumes $70 \%$ suppression during the $1^{\text {st }}$ step, whole body glucose disposal would be underestimated by $3 \mu \mathrm{mol} \cdot \mathrm{kg}^{-1} \cdot \mathrm{min}^{-1}$. If the suppression of HGP is less in the diabetic than in the control subjects during the $1^{\text {st }}$ step, e.g. $20 \%$ instead of $70 \%$, the underestimation of total glucose disposal would be 8 instead of $3 \mu \mathrm{mol} \cdot \mathrm{kg}^{-1} \cdot \mathrm{min}^{-1}$. Even then the difference $\left(5 \mu \mathrm{mol} \cdot \mathrm{kg}^{-1} \cdot \mathrm{min}^{-1}\right)$ is too small to account for the observed differences in SSGIRs of the $1^{\text {st }}$ step. Thus, the decrease in insulin action in the $1^{\text {st }}$ step cannot be entirely attributed to the liver. If on the other hand, as suggested by Hother-Nielsen et al. [22], insulin's ability to suppress HGP is increased, the decrease in peripheral insulin action may actually be even greater than we found.

Theoretically, one may postulate a different course of insulin resistance for peripheral insulin action and HGP. While peripheral tissues get insulin resistant from half a year, the liver may initially retain a normal (or even increased) response to insulin to become insulinresistant only later on. In the patients with 20 years diabetes, basal glucose was $8.5 \mathrm{mmol} / 1$ in spite of plasma insulin concentrations around $19 \mathrm{mU} / 1$, whereas in the groups with shorter durations of disease basal glucose was $5.0 \mathrm{mmol} / 1$ at similar insulin levels. As basal glucose is a function of HGP, basal HGP in the patients having 20 years diabetes might have been increased as a reflection of hepatic insulin resistance.

Interpretation of data regarding the cross-sectional study may be confounded by the difference in the age of onset of diabetes. Patients were matched with regard to sex, age and body weight. Since the mean duration of diabetes was 5,10 and 20 years and the average age was approximately 28 years, the mean age at onset was 23 , 18 and 8 years, respectively. Patients with an earlier onset of the disease may represent a different subgroup. However, a major influence on insulin action is unlikely because in the multiple regression analyses neither age nor duration of diabetes were significant correlates in any sub-set of clinical variables.

Despite treatment with human semi-synthetic insulin, antibodies to insulin developed within 3 months. The median percentage tracer binding in the prospective study group after 12 months was similar to that of the patients with longstanding disease, among which 5 used porcine and 1 bovine insulin. Insulin antibodies may account for the consistent finding of lower plasma free insulin levels during the clamps in the diabetic patients, as noted in other studies [3,10]. However, similar plasma free insulin levels were found in the newly diagnosed patients in the year during which their median percentage tracer binding increased from 0 to $13 \%$. Further, there was no significant correlation between percentage tracer binding and achieved insulin level during 
the clamp (data not shown). Finally, Waldhäusl et al. found no difference in free insulin levels in clamp studies of diabetic patients with high and low insulin binding capacities [35]. Thus, other factors must be involved to account for this difference between diabetic and control subjects.

The pathogenesis of insulin resistance may differ according to the stage of the disease. In newly diagnosed patients, a likely cause is insulin deficiency or its metabolic sequelae, such as raised counter-regulatory hormones, intermediary metabolites, ketoacids and free fatty acids or the presence of dehydration and hyperosmolality. The individual and combined effects of these factors are not clear at present [see Ref. 36]. Yet, it is conceivable that the insulin deficiency preceding the initiation of treatment caused abnormalities in insulin action, which were still manifest after two weeks of insulin therapy, as noted previously [15], but which were reversed during the first half-year.

In diabetes after 6,9 and 12 months, $\mathrm{HbA}_{1}$ and insulin requirement were inverse correlates for insulin action; in patients with longstanding disease, this was noted for $\mathrm{HbA}_{1}$ and body weight. In control subjects, body weight was inversely related to insulin action. This finding for body weight - in both diabetic and healthy subjects - underlines the well-known general role of obesity in modulating insulin action. Glycaemic control appears to play an important role in the diabetic patients. Other studies employing simple linear regression analysis also documented an inverse correlation between $\mathrm{HbA}_{1}$ and insulin action (e.g. [12]). This does, however, not demonstrate that the relation is causal. Nevertheless, there exist in vivo and in vitro data supporting a putative glucose-toxicity mechanism [37]. For example, insulin resistance improves, but does not normalise, when glycaemic control is improved by pump treatment $[10,21,38]$. A still rising amount of reports demonstrate in vivo and in vitro a role of glucose per se, as regulator of its own uptake [39-43]. Therefore, in view of accumulating evidence, hyperglycaemia per se must be considered as a factor for the development and persistence of insulin resistance in diabetes.

Because insulin is administered subcutaneously, by which means it initially by-passes the portal system, intermittent peripheral hyperinsulinaemia is an inevitable consequence of current insulin therapy, if (near) normoglycaemia is strived for [44]. Recent studies have shown that hyperinsulinaemia induces insulin resistance $[45,46]$. Thus the observed recurrence of insulin resistance could also partly be mediated by hyperinsulinaemia, created by current treatment. Our data do not add weight to this notion, except for the negative relation between insulin dose and insulin action at 6,9 and 12 months, and a negative rank correlation between basal plasma free insulin and SSGIR at the same timepoints (Spearman's rho from -0.23 to -0.55 , NS, data not shown). We do not know the degree of hyperinsu- linaemia in the patients, except that in order to maintain basal glucose at $5.0 \mathrm{mmol} / \mathrm{l}$, peripheral insulin levels of about $20 \mathrm{mU} / 1$ were needed.

In conclusion, decreased insulin sensitivity re-develops in Type 1 diabetes within the first year following an initial improvement. Presumably, hyperglycaemia plays a role in the pathogenesis of this recurrence.

Acknowledgements. The help of M. van Dijk-Besling for performing the radioimmunoassays is gratefully acknowledged. We thank Dr. J.H.M.Souverijn for the determination of fructosamine, and Dr. $\mathrm{Tj}$. Wieringa for many interesting discussions in the preparation of this manuscript. We thank the personnel of the Endocrine Department of the University Hospital Leiden for the excellent care given to all participants of the study. The study was supported by Novo Industri BV, Amsterdam, The Netherlands.

\section{References}

1. Barret EJ, DeFronzo RA, Bevilacqua S, Ferrannini E (1986) Insulin resistance in diabetic ketoacidosis. Diabetes 31: 1135-1146

2. Nankervis A, Proietto J, Aitken P, Alford F (1984) Impaired insulin action in newly diagnosed Type 1 (insulin-dependent) diabetes mellitus. Diabetologia 27: 497-503

3. Yki-Järvinen H, Koivisto VA (1984) Insulin sensitivity in newly diagnosed Type 1 diabetics after ketoacidosis and after three months of insulin therapy. J Clin Endocrinol Metab 59: 371-378

4. DeFronzo RA, Hendler R, Simonson DF (1982) Insulin resistance is a prominent feature of insulin-dependent diabetes. Diabetes 31 : 795-801

5. DeFronzo RA, Simonson D, Ferrannini E (1982) Hepatic and peripheral insulin resistance: a common feature of Type 2 (non-insulin-dependent) and Type 1 (insulin-dependent) diabetes mellitus. Diabetologia 23: 313-319

6. DelPrato S, Nosadini R, Tiengo A, Tessari P, Avogaro A, Trevisan R, Valerio A, Muggeo M, Cobelli C, Toffolo G (1983) Insulinmediated glucose disposal in Type 1 diabetes: evidence for insulin resistance. J Clin Endocrinol Metab 57: 904-910

7. Proietto J, Nankervis A, Aitken P, Caruso G, Alford F (1983) Glucose utilization in Type 1 (insulin-dependent) diabetes: evidence for a defect not reversible by acute elevations of insulin. Diabetologia 25: 331-335

8. Lager I, Lönnroth P, von Schenck H, Smith U (1983) Reversal of insulin resistance in Type 1 diabetes after treatment with continuous subcutaneous insulin infusion. Br Med J 287: 1661-1664

9. Pernet A, Trimble ER, Kuntschen F, Damoiseaux $\mathrm{P}$, Assal J-Ph, Hahn C, Renold AE (1984) Insulin resistance in Type 1 (insulindependent) diabetes: dependence on plasma insulin concentration. Diabetologia 26: $255-260$

10. Beck-Nielsen $H$, Richelsen $B$, Hasling C, Nielsen $O H$, Heding L, Sorensen NS (1984) Improved in vivo insulin effect during continuous subcutaneous insulin infusion in patients with IDDM. Diabetes 33: 832-837

11. Hansen IL, Cryer PE, Rizza RA (1985) Comparison of insulinmediated and glucose-mediated glucose disposal in patients with insulin-dependent diabetes mellitus and in nondiabetic subjects. Diabetes 34: 751-755

12. Yki-Järvinen $H$, Koivisto VA (1986) Natural course of insulin resistance in Type 1 diabetes. N Engl J Med 315: 224-230

13. Kahn CR (1978) Insulin resistance, insulin insensitivity and insulin unresponsiveness: a necessary distinction. Metabolism 27 [Suppl 2]: 1893-1902

14. Olefsky JM (1981) Insulin resistance and insulin action. An in vivo and in vitro perspective. Diabetes $30: 148-162$

15. Nijs HGT, Radder JK, Frölich M, Krans HMJ (1988) Insulin action is normalised in newly diagnosed Type 1 (insulin-dependent) 
diabetic patients in three months of insulin treatment. Metabolism 37: $473-478$

16. National Diabetes Data Group (1979) Classification and diagnosis of diabetes mellitus and other categories of glucose intolerance. Diabetes 28: 1039-1057

17. Rizza RA, Mandarino LJ, Gerich JE (1981) Dose-response characteristics for effects of insulin on production and utilization of glucose in man. Am J Physiol 240: E630-639

18. DeFronzo RA, Tobin JD, Andres R (1979) Glucose clamp technique: a method for quantifying insulin secretion and resistance. Am J Physiol 237: E214-223

19. McGuire EAH, Helderman JH, Tobin JD, Andres R, Berman M (1976) Effects of arterial vs venous sampling on analysis of glucose kinetics in man. J Appl Physiol 41: 565-573

20. Abumrad NN, Rabin D, Diamond MP, Lacy WW (1981) Use of a heated superficial hand vein as an alternative site for the measurement of amino-acid concentrations and for the study of glucose and alanine kinetics in man. Metabolism 30: 936-940

21. Simonson DC, Tamborlane WV, Sherwin RS, Smith JD, DeFronzo RA, for the Kroc Collaborative Study Group (1985) Improved insulin sensitivity in patients with Type 1 diabetes mellitus after CSII. Diabetes 34 [Suppl 3]: 80-86

22. Hother-Nielsen O, Schmitz O, Bak J, Beck-Nielsen H (1987) Enhanced hepatic insulin sensitivity, but peripheral insulin resistance in patients with Type 1 (insulin-dependent) diabetes. Diabetologia $30: 834-840$

23. Arner P, Bolinder J, Engfeldt P, Ostman J (1981) The antilipolytic effect of insulin in human adipose tissue in obesity, diabetes mellitus, hyperinsulinaemia and starvation. Metabolism 30: 753-760

24. Kuzuya H, Blix PM, Horwitz DL, Steiner DF, Rubenstein AH (1976) Determination of free and total insulin and C-peptide in insulin-treated diabetics. Diabetes 26: 22-29

25. Christiansen AH (1973) Radioimmunoelectrophoresis in the determination of insulin binding to IgG. Methodological studies. Horm Metabol Res 5: 147-154

26. Botazzo GF, Pujol-Borrell R, Doniach D (1981) Humoral and celIular immunity in diabetes mellitus. Clin Immunol Allergy 1: 139-159

27. Godfrey K (1985) Comparing the means of several groups. N Engl J Med 313: 1450-1456

28. Armitage R, Berry G (1987) Statistical methods in medical research. [ $2^{\text {nd }}$ Edition]. Blackwell, Oxford

29. Kleinbaum DG, Kupper LL (1978) Applied regression analysis and other multivariable methods. Duxbury Press, Boston Massachusetts, pp 227-234

30. Weisberg S, Bingham C (1975) An approximate analysis of variance test for non-normality suitable for machine calculation. Technometrics 17: 133-134

31. Revers RR, Kolterman OG, Scarlett JA, Gray RS, Olesfky JM (1984) Lack of in vivo insulin resistance in controlled insulin-dependent, Type 1, diabetic patients. J Clin Endocrinol Metab 58: 353-358

32. Tarn AC, Smith CP, Spencer KM, Bottazzo GF, Gale EAM (1987) Type 1 (insulin dependent) diabetes: a disease of slow clinical onset? Br Med J 294: 342-345

33. Yki-Järvinen H, Taskinen MR, Kiviluoto T, Hilden H, Helve E, Koivisto VA, Nikkilä EA (1984) Site of insulin resistance in
Type 1 diabetes: insulin-mediated glucose disposal in vivo in relation to insulin binding and action in adipocytes in vitro. J Clin Endocrinol Metab 59: 1183-1192

34. Ferrannini E, Buzzigoli G, Bonadonna R, Giorico MA, Oleggini M, Graziadei L, Pedrinelli R, Brandi L, Bevilacqua S (1987) Insulin resistance in essential hypertension. N Engl $J$ Med 317: 350-357

35. Waldhäusl WK, Bratusch-Marrain P, Kruse V, Jensen I, Nowotny $P$, Vierhapper H (1985) Effect of insulin antibodies on insulin pharmacokinetics and glucose utilization in insulin-dependent diabetic patients. Diabetes 34: 166-173

36. Pedersen O, Beck-Nielsen H (1987) Insulin resistance and insulindependent diabetes mellitus. Diabetes Care 10: 516-523

37. Unger RH, Grundy S (1985) Hyperglycaemia as an inducer as well as a consequence of impaired islet cell function and insulin resistance: implications for the management of diabetes. Diabetologia 28: 119-121

38. Lönnroth P, DiGirolamo M, Smith U (1983) Influence of ambient glucose and insulin concentrations on adipocyte insulin binding. Metabolism 32: 609-614

39. VanPutten JPM, Krans HMJ (1985) Glucose as a regulator of insulin-sensitive hexose uptake in 3T3 adipocytes. J Biol Chem 260: 7996-8001

40. Young DA, Uhl JJ, Cartee GD, Holloszy JO (1986) Activation of glucose transport in muscle by prolonged exposure to insulin. Ef fects of glucose and insulin concentrations. J Biol Chem 261: 16049-16053

41. Garvey WT, Olefsky JM, Matthaei S, Marshall S (1987) Glucose and insulin co-regulate the glucose transport system in primary cultured adipocytes. J Biol Chem 262: 189-197

42. Yki-Järvinen H, Helve E, Koivisto VA (1987) Hyperglycaemia decreases glucose uptake in Type 1 diabetes. Diabetes 36: 892-896

43. Rossetti L, Smith D, Shulman GI, Papachristou D, DeFronzo RA (1987) Correction of hyperglycaemia with phlorizin normalizes tissue sensitivity to insulin in diabetic rats. J Clin Invest 79: $1510-1515$

44. Hayford JT, Thompson RG (1982) Free and total insulin integrated concentrations in insulin dependent diabetes. Metabolism 31: 387-397

45. Marangou AG, Weber KM, Boston RC, Aitken PM, Heggie JCP, Kirsner RLG, Best JD, Alford FP (1986) Metabolic consequence of prolonged hyperinsulinaemia in humans. Diabetes 35: 1383-1389

46. Rizza RA, Mandarino LJ, Genest J, Baker BA, Gerich JE (1985) Production of insulin resistance by hyperinsulinaemia in man. Diabetologia 28: 70-75

Received: 26 July 1988

and in revised form: 28 November 1988

H.G.T. Nijs, M.D.

Department of Endocrinology and Metabolic Diseases

University Hospital, Bldg. 1, C4-R88

Rijnsburgerweg 10

2333 AA Leiden

The Netherlands 